\title{
AVALIAÇÃO DOS SISTEMAS DE PASTEJO EM PROPRIEDADES RURAIS DE LEITE EM CONFRESA-MT
}

\author{
EVALUATION OF GRAZING SYSTEMS IN RURAL MILK PROPERTIES IN \\ CONFRESA-MT
}

\author{
Sandra Aparecida Tavares ${ }^{1}$ (D), Tiago Cardoso de Oliveira ${ }^{2}$ (D), Leandro Batista Urzeda \\ Caetano $^{3}$ (D)
}

Recebido em 15 de Julho de 2020 | Aprovado em 17 de Dezembro de 2020.

\begin{abstract}
RESUMO
O manejo correto de uma pastagem é o fator determinante para uma boa produção e resposta por parte do animal. Assim o presente trabalho visou comparar o desenvolvimento dos sistemas rotacionado e extensivo de pastejo em propriedades rurais produtoras de leite do município de Confresa-MT. A metodologia do projeto buscou a aplicação de questionário, coleta de amostras de forragem, e acompanhamento da produção leiteira das doze propriedades escolhidas, as amostras de cada propriedade avaliada foram coletadas e encaminhadas para o laboratório de bromatologia do Instituto Federal de Mato Grosso - Campus Confresa, um total de 36 amostras de diferentes forrageiras avaliadas. Foram analisados três tratamentos, sistema rotacionado de pastejo com dois dias de ocupação, rotacionado com mais de dois dias de ocupação e sistema contínuo de pastejo. Segundo dados estatísticos ao teste de Tukey a 5\% o sistema rotacionado com 2 dias de ocupação apresentou resultados superiores em teores de massa verde, massa seca e produtividade leiteira em relação aos demais sistemas. Verificou se que o período de descanso foi fator primordial para tal resultado.
\end{abstract}

Palavras-chave: Avaliação; Sistema; Produtividade.

\begin{abstract}
The correct management of a pasture is the determining factor for a good production and response by the animal. Thus, the present work aimed to compare the development of rotational and extensive grazing systems in rural milk producing properties in the municipality of Confresa-MT. The methodology of the project sought the application of a questionnaire, collection of forage samples, and monitoring of milk production of the twelve chosen properties, the samples of each evaluated property were collected and sent to the bromatology laboratory of the Federal Institute of Mato Grosso - Campus Confresa , a total of 36 samples of different forages evaluated. Three treatments were analyzed, rotated grazing system with two days of occupation, rotated with more than two days of occupation and continuous grazing system. According to statistical data on the Tukey test at 5\%, the system rotated with 2 days of occupation showed superior results in contents of green mass, dry mass and milk productivity in relation to the other systems. It was found that the rest period was a major factor for this result.
\end{abstract}

Keywords: Evaluation; System; Productivity

\section{Introdução}

\footnotetext{
${ }^{1}$ Doutora em Produção Animal pela Instituição (UNESP). Professora na Instituição (IFSC), Canoinhas, Santa Catarina, Brasil. Endereço para correspondência: Rua Caetano Costa no 424, Centro, Canoinhas, Santa Catarina, Brasil, CEP 89640098. E-mail: sandra.tavares@ifsc.edu.br

${ }^{2}$ Graduado em Agronomia pelo IFMT, Confresa, Mato Grosso, Brasil. Endereço para correspondência: Avenida Mato Grosso, No52, Escritório Repórter Agro/Agência da Notícia, Jardim do Édem. Confresa, Mato Grosso, Brasil, CEP: 78652-000. E-mail: tiagoseiffert@gmail.com.

${ }^{3}$ Doutor em Produção Animal (UFGO), Professor da Instituição (IFMT), Confresa, Mato Grosso, Brasil. endereço para correspondência: Vilmar Fernandes n ${ }^{\circ}$ 300, Santa Luzia, Confresa, Mato Grosso, Brasil. CEP: Email: leandro.caetano@cfs.ifmt.edu.br
} 
A produção de leite é fundida por duas bases, tais bases se resumem entre o animal e o alimento fornecido para o mesmo, assim uma propriedade rural terá total sucesso em sua produção, aderindo a animais de qualidade e alimentação compatível. Com isso, entende-se que o sistema de pastejo e a qualidade dos animais são as chaves para o sucesso produtivo da cadeia leiteira.

Toda via a preocupação pelo aumento da produtividade de leite é o principal obstáculo dos produtores, sendo que a pastagem é essencial para o sucesso na produtividade, portanto a preocupação em estabelecer estratégias e tecnologias para melhor e maior aproveitamento das áreas de pastejo.

Segundo Embrapa (1999), caracterizam se como fatores essenciais à disponibilidade e qualidade da forragem de uma pastagem bem manejada para que se obtenha sucesso da pecuária. $\mathrm{O}$ rendimento dessa atividade está relacionado com a capacidade de suporte da pastagem, redução dos custos de produção, administração eficiente e melhoramento genético do rebanho.

Em um todo, entende se, que para todas as áreas sejam elas de cria, recria, engorda ou produção, se requer uma forrageira de qualidade, que possa de fato nutrir o animal e dar a ele potencial de produção.

Em relação as forrageiras tropicais, estratégias de manejo das pastagens tem sido baseada em características eco fisiológicas, o que tem demonstrado grande semelhança a resultados obtidos com plantas de clima temperado (VOLTOLINI et. al, 2010).

Conforme Neto (1994), existem vários pontos que influenciam na escolha de diferentes sistemas de pastejo. Alguns desses fatores a serem observados para a escolha do sistema de pastejo seja ele rotacionado ou extensivo são a espécie da forrageira, a taxa de lotação, além do tipo e disponibilidade de forrageira.

De acordo com Andrade (2008), é de suma importância o manejo correto das pastagens para qualquer sistema de criação de bovinos a pasto. Se existir um bom manejo da pastagem, geralmente as forrageiras presentes na mesma irão apresentar maiores taxas de crescimento, protegendo o solo e competindo diretamente com plantas invasoras, dispondo de vantagem sobre as mesmas. Sendo assim os custos com limpeza e manutenção destas pastagens será bem menor, além de contribuir é claro para uma melhor nutrição do rebanho, influenciando diretamente nos índices de produtivos, reprodutivos e sanitários.

Entende-se que a produção de leite ocupa grande importância na renda dos pequenos e médios produtores do município de Confresa, assim o sistema de rotação foi empregado, no 
intuito de diminuir os custos e aumentar a produtividade. Embasado neste contexto o projeto busca analisar e constatar a real interferência sobre os índices de período de lotação de vacas mestiças SRD (Sem Raça Definida) e Girolandas (surgidas do cruzamento entre as raças Gir e Holandesa) em sistemas diferentes de pastejo, comparando propriedades e avaliando índices de produtividade leiteira e massa verde e massa seca das pastagens.

\section{Metodologia}

O trabalho foi conduzido no município de Confresa - MT localizado uma latitude $10^{\circ} 38^{\prime} 38^{\prime \prime}$ sul e a uma longitude $51^{\circ} 34^{\prime} 08^{\prime \prime}$ oeste, estando a uma altitude de 240 metros, contendo precipitações superiores a $1.800 \mathrm{~mm}$ anualmente. Sua temperatura vária entre $19^{\circ} \mathrm{C}$ á $35^{\circ} \mathrm{C}$ com uma média de $27^{\circ} \mathrm{C}$. O desenvolvimento da pesquisa consistiu na avalição e comparação de doze propriedades rurais produtoras de leite do município.

A execução do trabalho foi embasada em visitas práticas a cada uma das propriedades avaliadas, aplicando um questionário in loco, com informações para o mapeamento qualitativo e quantitativo das propriedades em relação a produção de leite. Além disso, coletou amostras de forrageiras utilizadas para alimentação animal em cada área visitada afim de avaliar os valores bromatológicos.

O questionário buscou mapear a produção de leite de cada uma das propriedades, além de outras informações relevantes a respeito do tamanho da área de pastejo, tipo de forrageira utilizada, número total de animais, número de lactantes, produção diária total e individual por vaca, solo e armazenagem do produto final. O questionário ainda quantificou e classificou as raças dos animais, avaliando se existia melhoramento genético, seleção de animais e avanços tecnológicos no processo do rebanho leiteiro.

Já para coletas das amostras das forrageiras, se desenvolveu um quadrante de $1 \mathrm{~m}^{2}$, o mesmo foi lançado aleatoriamente pelas áreas de pastejo utilizada pelos animais, sendo que, no sistema rotacionado que contou em média com 24 piquetes, a escolha para coleta foi aleatória, afim de minimizar diferenças e avaliar como um todo a área. Já em áreas extensivas, as coletas se embasaram na obtenção de amostras em partes mais homogêneas de pastagem e que estivessem servindo como base alimentar aos animais em lactação, já que se tratavam de grandes áreas.

Para avaliação dos diferentes tipos de sistema, o projeto realizou a divisão em três categorias, sendo três propriedades com até dois dias de ocupação, três com mais de dois dias 
de ocupação e três propriedades com sistema continuo de pastejo. Assim totalizando 27 amostras.

A coleta das amostras consistiu no lançamento do quadrante, onde a área interna do mesmo compreendida a $1 \mathrm{~m}^{2}$, era totalmente preenchida pela parte foliar da forrageira, que posteriormente era totalmente coletada com o auxílio de uma ferramenta cortante, sequencialmente inserida em sacos de papel inumerados em ordem de coleta $(1,2,3)$ para armazenagem temporária da amostra. Após a coleta, as amostras permaneceram no prazo máximo de 3 horas dentro da embalagem.

O procedimento de análise das amostras ocorreu no laboratório de bromatologia. Primeiramente avaliou o peso da massa verde de cada uma das amostras com o uso de uma balança de precisão, tarando o peso do saco vazio e posteriormente observando e anotando o peso em quilogramas de cada uma das amostras, preenchendo o espaço no questionário de cada propriedade exclusivamente desenvolvido para isso.

Identificou se cada amostra, seu peso e a data de coleta, terminado tal processo, as amostras foram colocadas em estufa de ventilação de ar forçada a uma temperatura de $65^{\circ} \mathrm{C}$ por 72 horas para retirada de umidade.

Em média após as 72 horas de secagem, as amostras foram retiradas da estufa e novamente pesadas, afim de calcular o peso da massa seca das forrageiras selecionadas a campo.

Os resultados de produção leiteira foram obtidos através das informações colhidas durante as visitas in loco.

Para avaliar os dados de massa verde, massa seca e produtividade leiteira foram realizadas análises estatísticas pelo pacote computacional Sisvar for Windows (FERREIRA, 1999), o teste empregado para comparação dos valores médios foi Tukey a $5 \%$ de probabilidade.

\section{Resultados e Discussão}

Para teores de massa verde das forrageiras, verificou se na tabela 01 que áreas compostas por sistema de rotação de dias de ocupação (Rot I) apresentaram resultados superiores aos demais tratamentos.

Tabela 01- Médias de produção de massa verde (g) e massa seca (g) em diferentes pastejos: 


\begin{tabular}{ccc}
\hline Sistema de Pastejo & Massa Verde & Massa Seca \\
\hline Rot I & $199,25 \mathrm{a}$ & $58,45 \mathrm{a}$ \\
Rot II & $107,17 \mathrm{~b}$ & $26,81 \mathrm{~b}$ \\
Ext & $84,24 \mathrm{~b}$ & $34,88 \mathrm{~b}$ \\
\hline
\end{tabular}

Médias seguidas pela mesma letra na coluna, não diferem entre si pelo teste de Tukey a 5\% de probabilidade.

Ainda na Tabela 01, verificou se que o sistema Rot I, obteve resultados significativos se comparado aos demais sistemas. Assim valido ressaltar que o período de ocupação foi o fator decisivo para tais impactos na produção em massa das forrageiras avaliadas. Contudo, avaliouse que o tempo de ocupação de dois dias, apresenta o melhor resultado fisiológico para a planta e em produção para os animas, devido que, o determinado tempo de ocupação é o suficiente para a planta realizar seu ciclo fisiológico em relação a formação de folhas.

Voltolini et al. (2010) em seu trabalho com comparações semelhantes de dias de ocupação da área de pastejo também conclui que a implantação de dias de ocupação variáveis, em relação ao pastejo fixo, viabiliza a promoção por meio de aumento da desfolha, maiores ciclos de pastejo, proporcionando maior produção da forragem nos piquetes em utilização.

A principal forrageira adotada pelos produtores avaliados foi o Mombaça do gênero Panicum, onde, para que ocorra devida rebrota das plantas é necessário oprimir os perfilhos basais, isso se faz necessário para que se obtenham altos rendimentos e altas taxas de lotações, segundo (SANTOS, 1993), assim haverá maiores e melhores índices de massa verde por toda a forrageira (BARBOSA et al.,1996).

Além disso, outros trabalhos realizados com diferentes sistemas de pastejo, conferem que o dia de descanso é fator primordial para efeitos positivos sobre a produção do rebanho alocado ao sistema, conforme Santos et al. (2005) Observou-se pequena diferença numérica, com a maior produção de leite no segundo dia de ocupação, em razão da maior disponibilidade de folhas na pastagem no primeiro dia de ocupação, que reflete na produção de leite do dia seguinte.

Diante do estudo realizado, além das análises em relação as respectivas forrageiras, a produtividade das propriedades que compõem cada sistema também foi avaliada, seguindo em resultado concordante com a Tabela 01, na Tabela 02 em preposição aos níveis de produtividade, Rot I apresenta a maior significância na comparação aos demais tratamentos, com médias a 12 kg/UA, logo que, Santos (2005) obteve resultados próximos com dois dias de ocupação, onde se verificou $10,3 \mathrm{~kg}$ e $10,4 \mathrm{~kg}$ por UA. 
Tabela 02 - Produtividade em leite nos diferentes sistemas de pastejo:

\begin{tabular}{cc}
\hline Sistema de Pastejo & Produtividade por UA \\
\hline Rot I & $11,60 \mathrm{a}$ \\
Rot II & $7,73 \mathrm{~b}$ \\
Ext & $5,35 \mathrm{c}$
\end{tabular}

Médias seguidas pela mesma letra na coluna, não diferem entre si pelo teste de Tukey a 5\% de probabilidade.

De acordo com Marshin (1994), a recomendação do sistema rotacionado vem sendo feita devido a pressuposição necessária em que as plantas devem ter um determinado período de descanso a fim de completar seu processo, afim de recuperar ou aumentar os níveis de energia tanto nas raízes quando da coroa raízes da planta, com isso ocorrera a regeneração da pastagem sem a presença de animais e eventual extinção da espécie ali presente.

O questionário complementou a coleta das amostras, pois o mesmo foi criteriosamente disposto com perguntas especificas a respeito do tamanho da área de pastejo que variou entre 1 a 4 hectares para pastejo rotacionado, e superior a 4 hectares para áreas de pastejo extensivo. $\mathrm{O}$ questionário também abordou, se havia utilização de adubos e correções sobre as áreas, como o uso ureia, gesso, calcário e demais adubos.

Verificou-se com a aplicação do presente questionário, que ao total das propriedades componentes de sistema de pastejo rotacionado, 50\% delas utilizam uma área de 0 a 2 hectares, enquanto a outra parte se divide a uma área entre 2 a 4 hectares. Já em sistemas de pastejo extensivo, $100 \%$ das propriedades avaliadas utilizam áreas >4 hectares, sendo em média espaços entre 48 ha á 96 ha.

Conforme o espaçamento apresentado anteriormente, os animais dispostos no sistema rotacionado apresentam altos índices de produção, sendo que 25\% 50 a 100 litros/dia, 25\% 150 litros/dia e 50\% entre 100 a 150 litros/dia. Enquanto que em áreas de pastejo extensivo, as propriedades que correspondem a área de pastejo mencionado anteriormente possuem uma produção onde $50 \%$ respondem por 0 a 50 litros/dia e $50 \%$ a valores de 50 a 100 a litros/dia.

Com isso, os presentes dados sustentam os resultados de produtividades disponibilizados na Tabela 02, concluindo que os resultados em Rot I apresentaram os melhores índices, seguido de Rot II e por terceiro e piores valores obtidos se tem o sistema de pastejo extensivo.

Procurou se com a aplicação do questionário analisar as informações obtidas dos produtores nos diferentes tipos de manejo. As perguntas foram objetivas e diretas, cabendo a cada produtor responder conforme os resultados refletidos em sua propriedade. Conforme demonstrado na figura 01: 
Figura 01 - Questionário comparativo entre diferentes sistemas de pastejo:

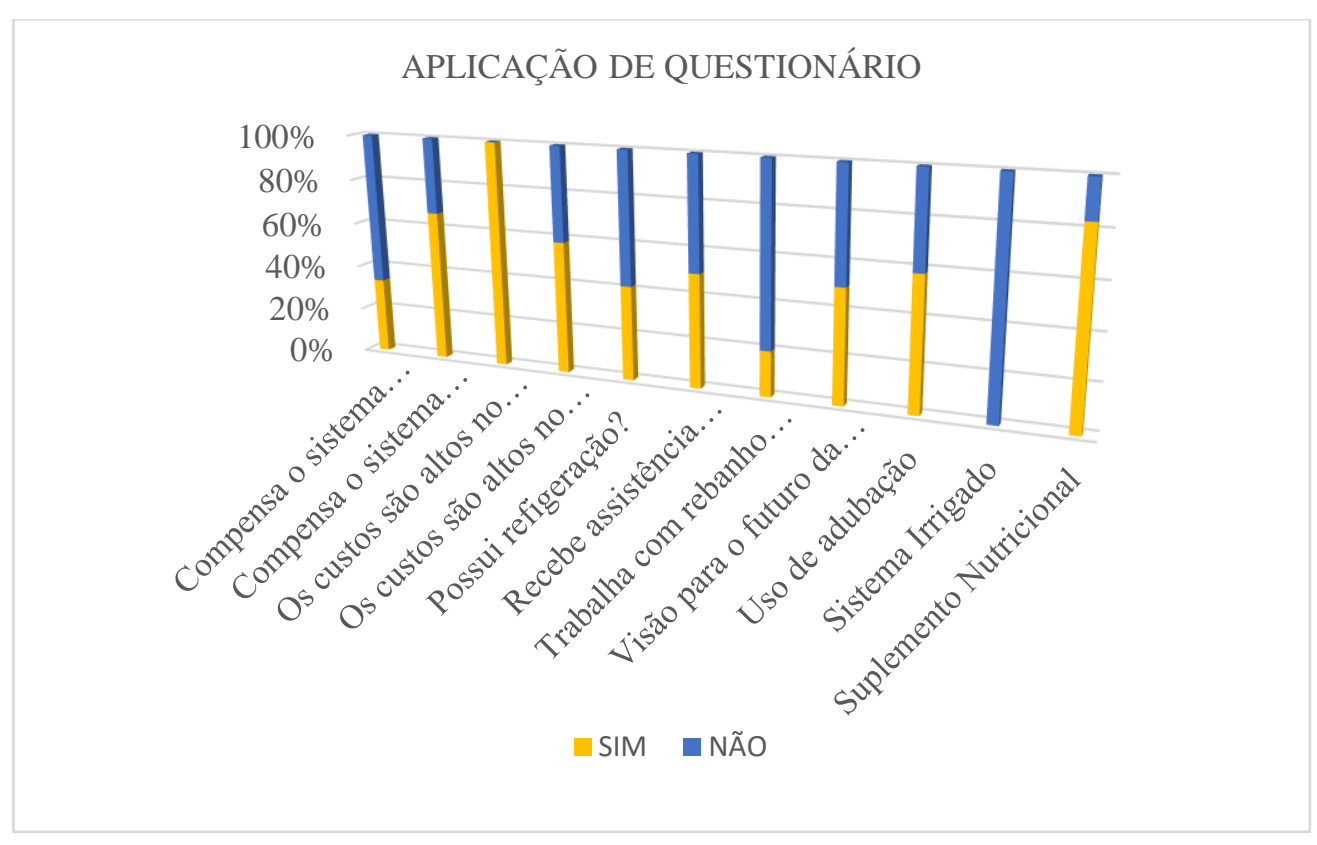

Fonte: Pesquisa a campo. Confresa-MT.

O presente gráfico evidencia que mais de $60 \%$ dos produtores de leite avaliados e acompanhados acreditam que o sistema rotacionado é vantajoso em relação ao extensivo, os mesmos produtores ainda assim descrevem serem altos os investimentos para desenvolvimento do sistema e além do retorno em longo prazo. Ainda assim, mesmo todos não estando inseridos no sistema a maioria buscam pela utilização de complementos minerais aos animais, e uso de alguma adubação sobre o solo.

Já em relação a seleção de rebanho melhorado, recebimento de assistência técnica e especializada, mais de $60 \%$ dos produtores se encontram nesta situação, sendo que muitos descreveram estarem sem assistência a vários meses, devido questões de logística por parte do órgão prestador de serviços.

As raças predominantes nas propriedades são girolando e mestiças, variando em animais melhorados e não melhorados, sendo que na maioria das localidades os animais são mestiços.

\section{Análises e Resultados}

Espera que a partir desse estudo outros surjam para melhor aprofundamento dessa temática que é de suma importãncia aos produtores de leite do município de Confresa. Estudos que possam caracterizar os produtores e avaliar o melhor sistema para situação. 


\section{Considerações}

Dentre os sistemas avaliados, o sistema Rotacionado I que se refere ao período de ocupação de dois dias por animais apresentou melhores resultados comparados aos demais tratamentos, demostrando a superioridade desse sistema.

O período de ocupação foi o fator chave para destaque em todos os seguimentos do pastejo rotacionado I em comparação aos demais, assim vale ressaltar que se realizado devidamente conforme as condições edafológicas da cultura e as condições de solo, é possível se obter uma taxa de lotação, com altas produtividades em seu rebanho.

\section{Agradecimentos}

O presente trabalho foi realizado com apoio da Coordenação de Aperfeiçoamento de Pessoal de Nivel Superior - Brasil (CAPES) - Código de Financiamento 001, através de bolsas concedidas ao discente.

E ao Instituto Federal do Mato Grosso, campus Confresa por ceder suas instalações para realização do experimento.

\section{Referências}

ANDRADE, C. M. S. de. Pastejo rotacionado: tecnologias para aumentar a produtividade de leite e a longevidade das pastagens. Embrapa Acre. 2008. Disponível em: <http://ainfo.cnptia.embrapa.br/digital/bitstream/item/107181/1/pastejo-mauricio.pdf >. Acesso em: 25 fev. 2018.

BARBOSA, M.A.A.F.; DAMASCENO, J.C.; CECATO, U. Estudo de perfilhamento em quatro cultivares de Panicum maximum Jacq. Submetidos a duas alturas de corte. In: REUNIÃO ANUAL DA SOCIEDADE BRASILEIRA DE ZOOTECNIA, 33., Fortaleza, 1996. Anais. Fortaleza: SBZ, 1996. v.2.

CPT.Pastejo rotacionado: Um avanço na tecnologia de manejo de pastagens para garantir a produtividade sustentável do sistema de produção e do agronegócio, o correto manejo de pastos é fundamental. Disponível em: <https://www.cpt.com.br/cursos-bovinospastagensealimentacao/artigos/pastejo-rotacionado-avanco-tecnologia-manejo-pastagens $>$. Acesso em 22 mar. 2018

EMBRAPA. Pastejo rotacinado intensivo para produção de leite. Belém - Pará, 1999. Disponivel em: < https://www.embrapa.br/busca-de-publicacoes/-/publicacao/377232/pastejorotacionado-intensivo-para-producao-de-leite>. Acesso em: 20 mar. 2018. 
MANFRIN, Eduardo. Et. al. Manejo do pastejo e suplementação concentrada sobre a produção de bovinos de corte a pasto: transição cerrado - AMAZÔNIA. Disponível em: <Http://www.nutritime.com.br/arquivos_internos/artigos/ARTIGO243.pdf>. Acesso em: 20 mar. 2018.

MARSCHIN, G. E. Sistema de pastejo 1. In: PEIXOTO, A. M. ; MOURA, J. C.; FARIA, V.(ed.). Pastagens: Fundamentos da Exploração Racional. Piracicaba: FEALQ,1994 a. p.337376.

MINERTHAL. Pastejo rotacionado ou contínuo: Qual a melhor opção?. Disponível em: $<$ http://www.minerthal.com.br/wp-content/uploads/Pastejo-rotacionado-econt\%C3\%ADnuo.pdf >. Acesso em 20 mar. 2018.

MULLER, M. S. et al. Produtividade do Panicum maximum cv. mombaça irrigado, sob pastejo rotacionado. USP/ESALQ, Sci. agric. (Piracicaba, Braz.) vol.59 no.3 Piracicaba July/Sept. 2002 Disponível em: $<$ http://www.scielo.br/scielo.php?script=sci_arttext\&pid=S010390162002000300003\&lng=en\&nrm=iso\&tlng=pt>. Acesso em: 20 mai. 2018

NETO, M. S. Sistema de pastejo 2. In: PEIXOTO, A. M. ; MOURA, J. C.; FARIA,V.(ed.). Pastagens. Lavras-MG, 1986.

PENATI, Marco Antônio; ONISH, Alexander Ryoji; RODRIGUES, Katia Fernanda Dias. Manejo econômico da pecuária leiteira. Piracicaba-SP, 2013. Disponível em:

$<$ http://www.esalq.usp.br/cprural/boapratica/mostra/80/manejo-economico-da-pecuarialeiteira.html>. Acesso em: 15 de abr. 2018

SANTOS, Andréa Luciana dos. Et al. Efeito do Dia de Ocupação sobre a Produção Leiteira de Vacas Mestiças em Pastejo Rotacionado de Forrageiras Tropicais. Revista Brasileira de Zootecnia, v.34, n.3, 2005. 1051-1059 p.

VIDAL, M. D.; COSTA, T. V. da. Implantação de sistema agrosilvipastoril em propriedades familiares do município de Careiro da Várzea - AM. Revista Brasileira de Agroecologia, v. 2, n. 2, 2007. 1000-1003 p.

VOLTOLINI, Tadeu et al. Produção e composição do leite de vacas mantidas em pastagens de capim-elefante submetidas a duas frequências de pastejo. Revista Brasileira de Zootecnia, v.39, n.1, 2010. 121-127 p. Disponivel em: <www.scielo.br/pdf/rbz/v39n1/16.pd>. Acesso em: 10 fev. 2018. 